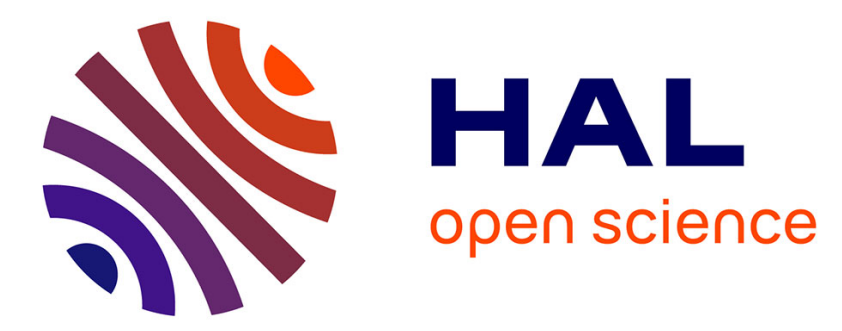

\title{
CFRP drilling: Fundamental study of local feed force and consequences on hole exit damage
}

Cédric Bonnet, Gérard Poulachon, Joël Rech, Yannick Girard, Jean-Philippe Costes

\section{To cite this version:}

Cédric Bonnet, Gérard Poulachon, Joël Rech, Yannick Girard, Jean-Philippe Costes. CFRP drilling: Fundamental study of local feed force and consequences on hole exit damage. International Journal of Machine Tools and Manufacture, 2015, 94, pp.57-64. 10.1016/j.ijmachtools.2014.04.006 . hal01169595

\section{HAL Id: hal-01169595 \\ https://hal.science/hal-01169595}

Submitted on 29 Jun 2015

HAL is a multi-disciplinary open access archive for the deposit and dissemination of scientific research documents, whether they are published or not. The documents may come from teaching and research institutions in France or abroad, or from public or private research centers.
L'archive ouverte pluridisciplinaire HAL, est destinée au dépôt et à la diffusion de documents scientifiques de niveau recherche, publiés ou non, émanant des établissements d'enseignement et de recherche français ou étrangers, des laboratoires publics ou privés. 


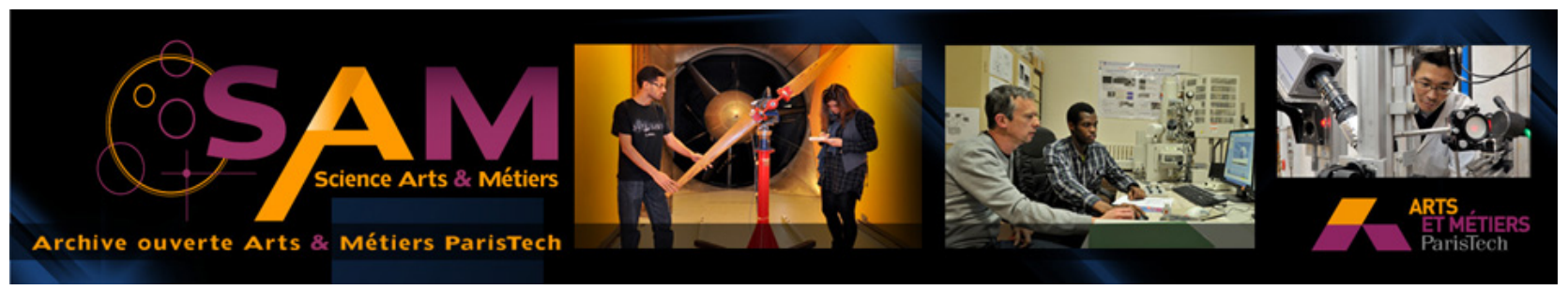

\section{Science Arts \& Métiers (SAM)}

is an open access repository that collects the work of Arts et Métiers ParisTech researchers and makes it freely available over the web where possible.

This is an author-deposited version published in: http://sam.ensam.eu

Handle ID: .http://hdl.handle.net/10985/9663

\section{To cite this version :}

Cédric BONNET, Gérard POULACHON, Joël RECH, Yannick GIRARD, Jean-Philippe COSTES CFRP drilling: Fundamental study of local feed force and consequences on hole exit damage International Journal of Machine Tools and Manufacture - Vol. 94, p.57-64 - 2015 


\title{
CFRP drilling: Fundamental study of local feed force and consequences on hole exit damage.
}

\author{
Cédric Bonnet ${ }^{\mathrm{a}, *}$, Gérard Poulachon ${ }^{\mathrm{a}}$, Joël Rech ${ }^{\mathrm{b}}$, Yannick Girard ${ }^{\mathrm{c}}$, Jean Philippe Costes ${ }^{\mathrm{a}}$ \\ a Arts et Metiers ParisTech, LaBoMaP, rue Porte de Paris, 71250 Cluny, France \\ ${ }^{\mathrm{b}}$ Université de Lyon, ENISE, LTDS, CNRS UMR5513, 58 rue Jean Parot, 42000 Saint-Etienne, France \\ c EADS IW, 12 bis, rue Pasteur, 92152 Suresnes Cedex, France
}

Keywords:

Drilling

Carbon fibers

Delamination

Modeling

Structural composites

\begin{abstract}
A B S T R A C T
Carbon Fiber-Reinforced by Plastic (CFRP) is now commonly used in the aircraft industry. The main challenge is to manufacture this difficult-to-cut work material, considering its quality criteria and economical aspects. Drilling is the main machining operation required for the assembly of the aircraft structure. In this paper, results are presented and discussed regarding exit delamination studied at a local scale. Because of the anisotropic properties of CFRP, the fiber cutting modes change with the composite sequence combined with the drill revolution parameters. The local feed forces generated by the cutting edge on the hole bottom may be correlated with delaminating aspects. A posttreatment method is proposed to analyze precisely these feed force and cutting torque distributions. Appropriate ply sequences are identified in order to limit the mechanical load concentration and the risk of delamination or uncut fibers
\end{abstract}

\section{Introduction}

Due to the demands of the aerospace industry, the lightweight and mechanical properties of materials have gained increasing importance in recent years. Carbon Fiber-Reinforced Plastic (CFRP) clearly satisfies these objectives and is now widely used in aerospace structure parts (50\% in terms of mass for the AIRBUS A350, versus $5 \%$ twenty years ago). The challenge is now to produce series of parts with limited manufacturing costs and a high quality level. Machining operations are particularly risky because they may reduced structural strength and hence affect fatigue life, according to Persson [1]. The first studies related to CFRP machining were undertaken in the 1980s, whereas metallic alloy research started in the 1950s. The literature shows little fundamental understanding of this composite material. Wang [2] and Arola [3] proposed the first approach to fiber cutting mechanisms in orthogonal trimming. They underlined that fiber orientation has a significant effect on surface quality.

In the particular case of CFRP drilling operations, the main difficulty is focused on exit defects. Vijayan [4], Piquet [5] and Davim [6] agree with the idea that reducing the delamination of CFRP is linked with a decrease in the feed force. Zitoune [7] has

\footnotetext{
* Corresponding author.

E-mail addresses: cedric bonnet@yahoo.fr (C. Bonnet) gerard.poulachon@ensam.eu (G. Poulachon), rech@enise.fr (J. Rech), jean-philippe.costes@ensam.eu (J.P. Costes).
}

worked on a numerical model to predict the macroscopic feed force, and correlates it with fracture mechanisms. Tsao [8] has proposed more efficient drill design, such as the saw drill, candlestick drill and abrasive tools commonly used in wood machining. Unfortunately, this kind of geometry cannot satisfy the recent demands of aerospace concerning CFRP/Titanium/Aluminum stack drilling. As explained by Ramulu [9], conventional twist drill geometries are more appropriate and must be improved to be in conformance with metallic and composite specifications.

In order to study the interaction between the cutting edge and the work material at the end of the operation, some authors consider the CFRP as an isotropic work material, like metallic alloys. However, carbon fiber is one of the most anisotropic materials. Longitudinal rupture strength reaches more than $5000 \mathrm{MPa}$, whereas shear strength is negligible. As illustrated in Fig. 1, CFRP is an inhomogeneous work material. Carbon fibers of $5 \mu \mathrm{m}$ diameter are bonded with an epoxy resin to form unidirectional plies of $250 \mu \mathrm{m}$ thickness, superposed and oriented according to a sequence of plies determined by the designer with respect to the final use of the part. The mechanical properties are thus given by the intrinsic resistance of the fibers, i.e. a high resistance in the longitudinal direction compared to the radial one. However, machining capacities are never considered at this design stage. The last ply is sometimes composed of glass fiber in order to avoid exit delamination, but its efficiency is often limited if the cutting conditions are severe.

Consequently the present article proposes a study at the local 


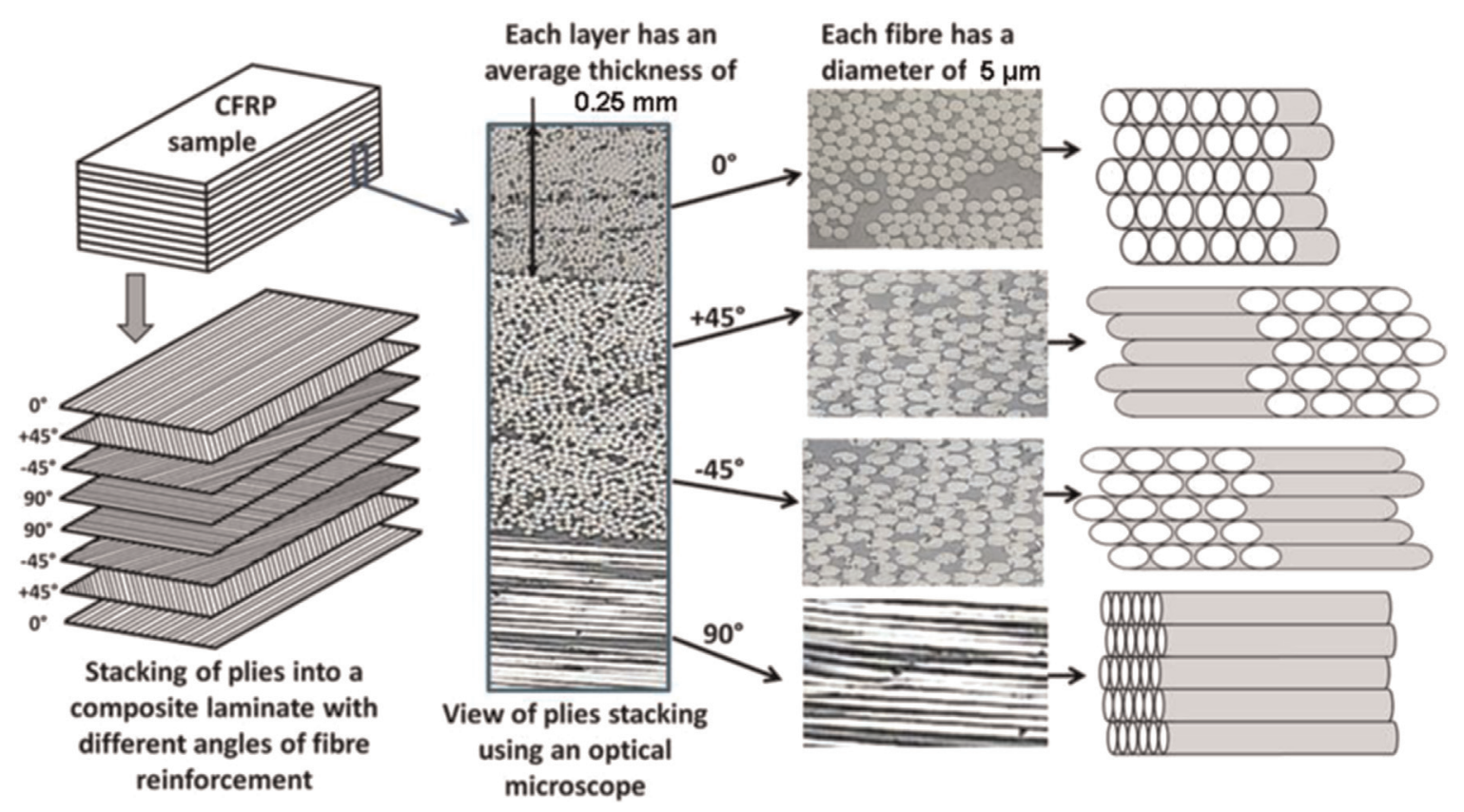

Fig. 1. Ply sequence of a CFRP, illustrated by Mondelin [10].

Table 1

Design of the selected MD\&UD CFRP samples.

\begin{tabular}{|c|c|c|c|c|c|c|c|c|c|}
\hline Ply number & 1 & 2 & 3 & 4 & 5 & 6 & 7 & 8 & 1 \\
\hline $\begin{array}{l}\text { Depth }(\mathrm{mm}) \\
\text { Angle } \theta(\mathrm{deg})\end{array}$ & 0 & 0.25 & 0.5 & 0.75 & 1 & 1.25 & 1.5 & 1.75 & $\ldots 2$ \\
\hline $\begin{array}{l}\text { Sample no. } \\
1 \text { Multidirectional }\end{array}$ & $0^{\circ}$ & $0^{\circ}$ & $+45^{\circ}$ & $-45^{\circ}$ & $90^{\circ}$ & $0^{\circ}$ & $0^{\circ}$ & $+45^{\circ}$ & $\ldots$ \\
\hline $\begin{array}{l}\text { Sample no. } \\
2 \text { Unidirectional }\end{array}$ & $0^{\circ}$ & $0^{\circ}$ & $0^{\circ}$ & $0^{\circ}$ & $0^{\circ}$ & $0^{\circ}$ & $0^{\circ}$ & $0^{\circ}$ & $\ldots$ \\
\hline
\end{tabular}

Table 2

Definition of the designed drill geometries.

\begin{tabular}{llll}
\hline Twist drill & $\# 1$ & $\# 2$ & $\# 3$ \\
Tip angle $\left(2 \kappa_{\mathrm{r}}\right)$ & $90^{\circ}$ & $110^{\circ}$ & $140^{\circ}$ \\
Coating & CVD Diamond & \\
Standard reference & SECO SD203 - Ø12 mm & \\
\hline
\end{tabular}

scale. It is a novel approach with respect to the literature, because the effect of the instantaneous fiber orientation on the cutting edge is now taken into account to model the local feed force and the consequences in terms of delamination. First of all, an experimental approach investigates hole exit damage for different drill geometries and various cutting parameters. Then a specific model is proposed to analyze the feed force signal and identify the mechanical load generated by the cutting edge over the exit ply at each angular position of the drill. Finally, a discussion is proposed to make a correlation between the local feed force and the geometry of the hole exit defect.

\section{Experimentation}

\subsection{Set up}

The investigated work material is firstly a multidirectional (MD) CFRP made of 140 plies of carbon fiber T800 embedded in M21epoxyde resin. This first sample is made of an alternation of different fiber orientations, representative of the design used in the aerospace industry. The second one is a unidirectional (UD) sample designed only for scientific needs in order to study the effects of the fiber orientation near the exit surface. Both samples are described in Table 1.

A standard tungsten carbide twist drill with two flutes and a CVD diamond coating was used. The SECO SD203 tool was modified in order to test different tool tip angles, as illustrated in Table 2.

Measurements of cutting forces were performed using a Kistler 9123C piezoelectric dynamometer with a large bandwidth (0-7 $800 \mathrm{~Hz})$.

\subsection{Exit surface examination}

The exit surface defects in the multidirectional CFRP sample no. 1 for various feed rates, cutting speeds and tip angles are presented in Fig. 2.

A specific criterion is proposed to characterize the quality of the exit surface by the maximum ring damage $\left(D_{\max }\right)$ and the angular delamination zone $\left(\chi_{2} \min ; \chi_{2} \max \right)$, as defined in Fig. 3.

The $\chi_{2}$ angle represents the various cutting modes as illustrated in Fig. 4. It is measured between the cutting velocity vector and the fiber direction. To conform to the convention defined by McKenzie [11], $\chi_{2}$ is positive in the trigonometric orientation. In the particular case of a CFRP drilling operation, $\chi_{2}$ changes continuously during a half-revolution of the cutting edge.

As illustrated in Fig. 5, the drill tip angle $\left(2 \kappa_{\mathrm{r}}\right)$ has a significant influence because delamination can be avoided if $2 \kappa_{\mathrm{r}}$ is less than $110^{\circ}$. Otherwise, delamination increases with the feed rate. Above $0.05 \mathrm{~mm} / \mathrm{rev}$, it exceeds the maximum damage ring of $\varnothing 14 \mathrm{~mm}$ authorized by the aerospace industry in the case of $\varnothing 12 \mathrm{~mm}$ diameter. The cutting speed also affects the maximum damage ring. The best results are thus obtained at high cutting velocities ( Vc $>100 \mathrm{~m} / \mathrm{min})$, with a low feed rate $(f<0.05 \mathrm{~mm} / \mathrm{rev})$ and thin tip angles $\left(2 \kappa_{\mathrm{r}}<110^{\circ}\right)$.

The angular delamination area is illustrated in Fig. 6. The defect is not homogeneous around the hole perimeter and appears systematically between angles $\chi_{2} \min =-10^{\circ}$ to $\chi_{2} \max =90^{\circ}$. These results are in agreement with the observations made by Ghidossi [12] and may not be influenced by the feed rate and the cutting speed. Concerning the drill geometry, it is clearly confirmed that a thin tip angle is the best way to avoid delamination. 


\section{Multidirectional CFRP T800M21 Tungsten carbide twist drill $\varnothing 12$ With CVD diamond coating}

a

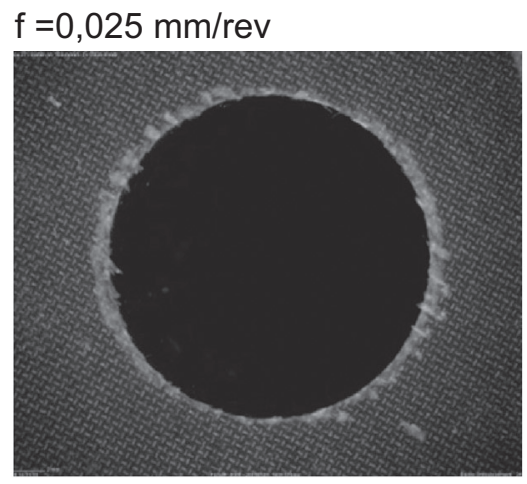

b

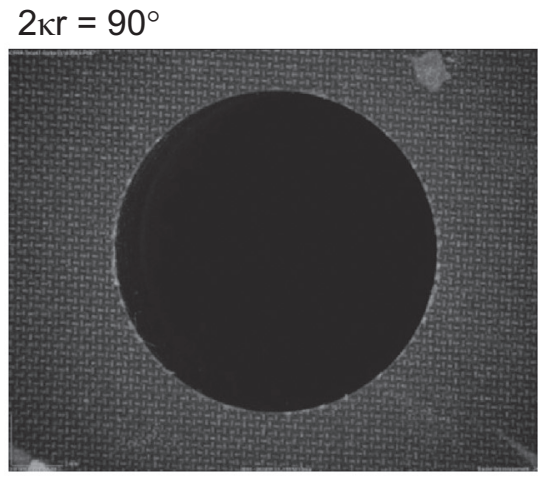

C

$\mathrm{Vc}_{\mathrm{c}}=200 \mathrm{~m} / \mathrm{min}$

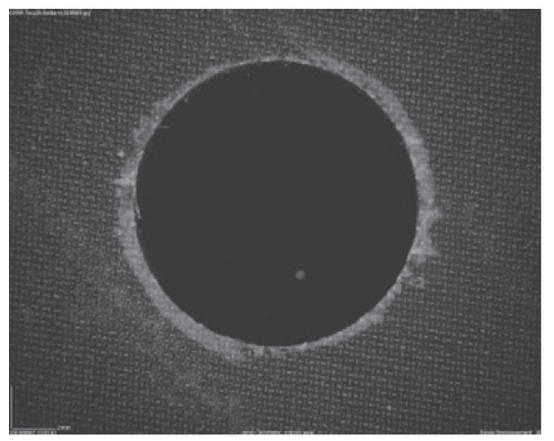

$$
f=0,05 \mathrm{~mm} / \mathrm{rev}
$$

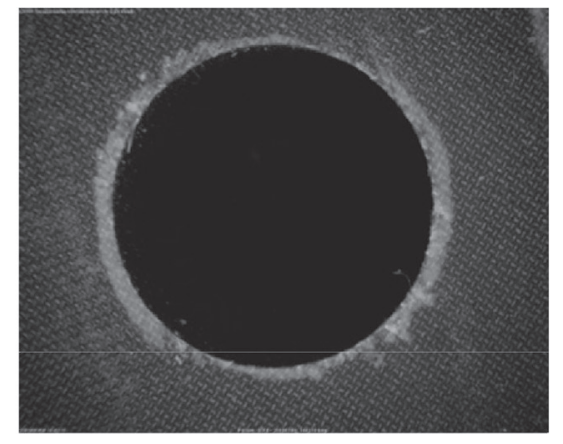

$$
2 \kappa r=110^{\circ}
$$

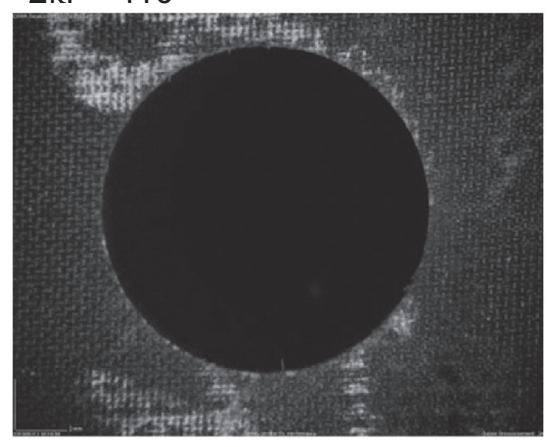

$\mathrm{Vc}=50 \mathrm{~m} / \mathrm{min}$

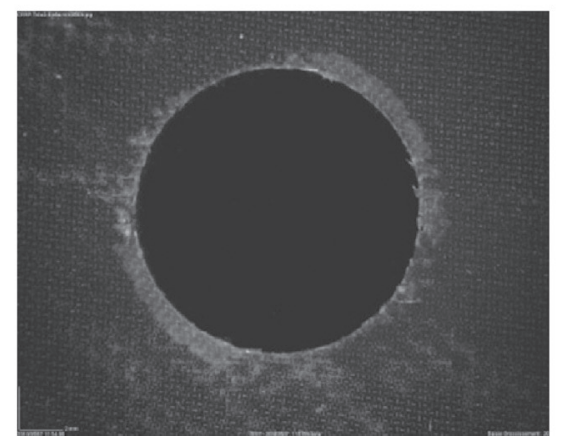

$\mathrm{f}=0,1 \mathrm{~mm} / \mathrm{rev}$

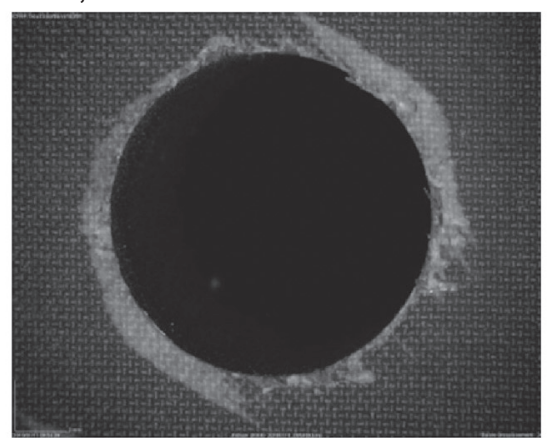

$2 \kappa r=140^{\circ}$

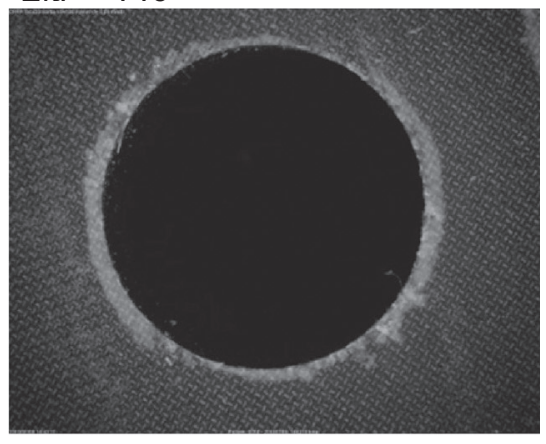

$\mathrm{Vc}=10 \mathrm{~m} / \mathrm{min}$

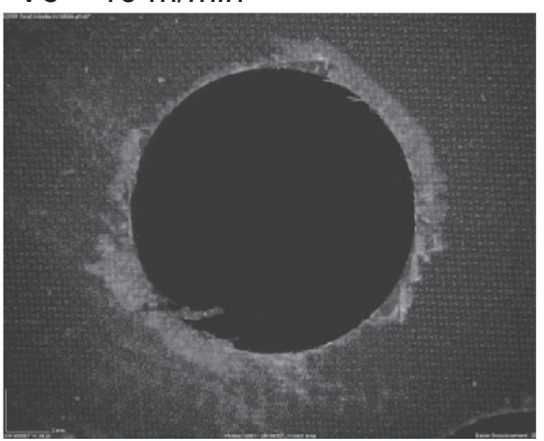

Fig. 2. Observation of the exit surface with respect to $f, V_{\mathrm{c}}$ and $2 \kappa_{\mathrm{r}}$.

\subsection{Force measurement}

The signals of the feed force and the cutting torque measured in CFRP drilling are extremely scattered, as illustrated in Fig. 7. Contrary to homogeneous work materials, the amplitude of the signal is very large: respectively $70 \%$ and $30 \%$ for the average feed force and the average torque. This should not be considered as noise, but as the consequence of the fiber cutting modes investigated by Wang [1].

The cutting mode effect can be filtered using a low pass filter $(10 \mathrm{~Hz})$, as indicated in Fig. 8. This frequency was chosen with respect to the revolution frequency, which is close to $10 \mathrm{~Hz}(13 \mathrm{~Hz})$ in the specific case where the cutting speed is set to $30 \mathrm{~m} / \mathrm{min}$. The transient signal is thus eliminated and will be studied later. In this way, the different steps of the drilling operation can easily be identified. From \#A to \#B, the feed force $F z$ and the cutting torque $\mathrm{Mz}$ increase gradually because of the progressive engagement of the cutting edge. As discussed by Claudin [13], this variation depends on the drill tip geometry. From \# B to \# C, the feed force is stabilized, whereas the torque continues to increase. According to Ghidossi [12], this phenomenon is due to the elastic recovery of the fiber on the margins. The contact length between the inner wall and the margin depends on the drill back taper angle. At \# C, the drilling process is stabilized until reaching the exit surface \#D. The progressive tip exit is also observed between \#D and \#E. The feed force gradually decreases to zero, with an inverse behavior to that previously observed during tip entry. From \#E to \#F, the fiber's elastic recovery generates a residual torque during the 


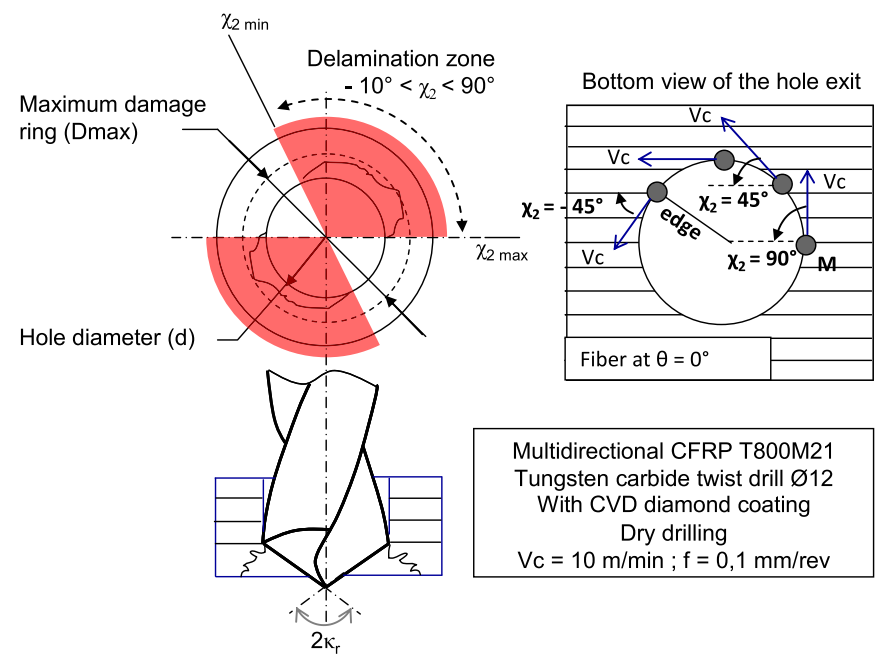

Fig. 3. Definition of damage criteria during CFRP drilling.

margin exit.

The feed force was studied at various feed rates, drill tip angles and cutting speeds, for the multidirectional CFRP no. 1. In order to compare the different geometrical configurations, the average linear feed force $\left(\mathrm{dF}_{\mathrm{z}}\right)$ along the cutting edge is calculated using the maximum feed force measured at \# B, divided by the length of the engaged cutting lip. The results of this investigation are presented in Fig. 9. The minimum average linear feed force is estimated at $20 \mathrm{~N} / \mathrm{mm}$ with a $90^{\circ}$ tip angle. Increasing the drill tip angle from $90^{\circ}$ to $140^{\circ}$ increases the linear feed force by $+75 \%$. The feed rate has a significant effect because the elementary $\mathrm{d} F z$ force increase is about $+35 \%$ from 0.025 to $0.1 \mathrm{~mm} / \mathrm{rev}$. Concerning the influence of cutting speed, the results underline that highspeed cutting slightly reduces the average linear feed force. The lowest value of DFz may be obtained at high cutting velocities $\left(V_{\mathrm{c}}>100 \mathrm{~m} / \mathrm{min}\right)$, with a low feed rate $(f<0.05 \mathrm{~mm} / \mathrm{rev})$ and thin tip angles $\left(2 \kappa_{\mathrm{r}}<110^{\circ}\right)$. The correlation with exit delamination will be discussed later.

\section{Modeling of the local distribution of the feed force}

A model is proposed to ascertain the local linear feed $(\mathrm{d} F z)$ force generated by the cutting edge. In case of CFRP drilling, it cannot be observed by using only an experimental approach because the fiber cutting mode $\chi_{2}$ changes continuously according to the composite arrangement and the curvilinear position along the cutting edge $(l)$, illustrated in Fig. 10. Moreover, the drill lip cuts several plies at the same time because its length is greater than a ply thickness, and will thus introduce a discontinuity in the local

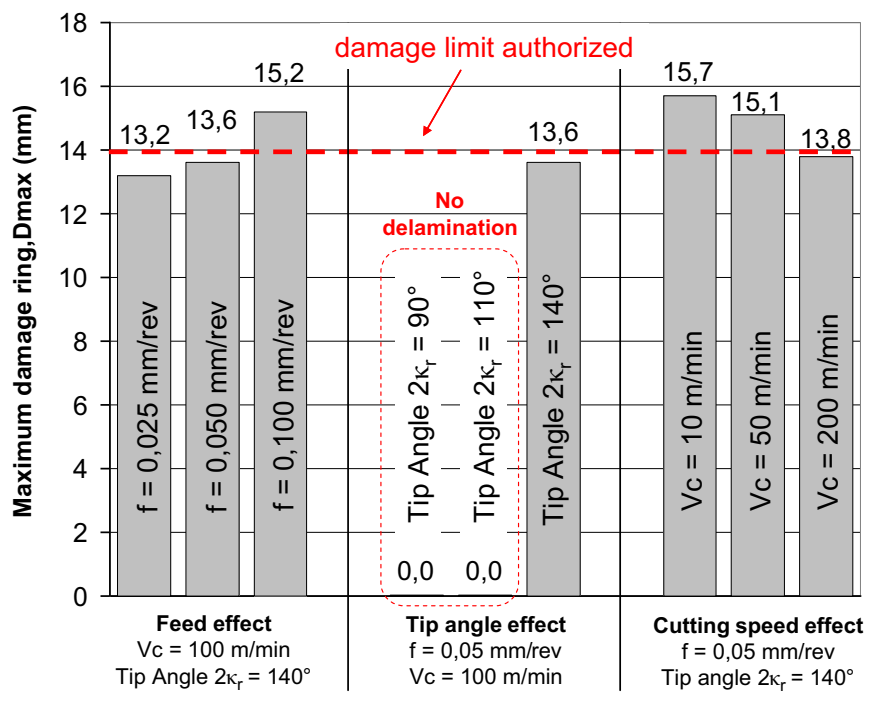

Fig. 5. Variation in the maximum damage ring versus feed tip angle and cutting speed.

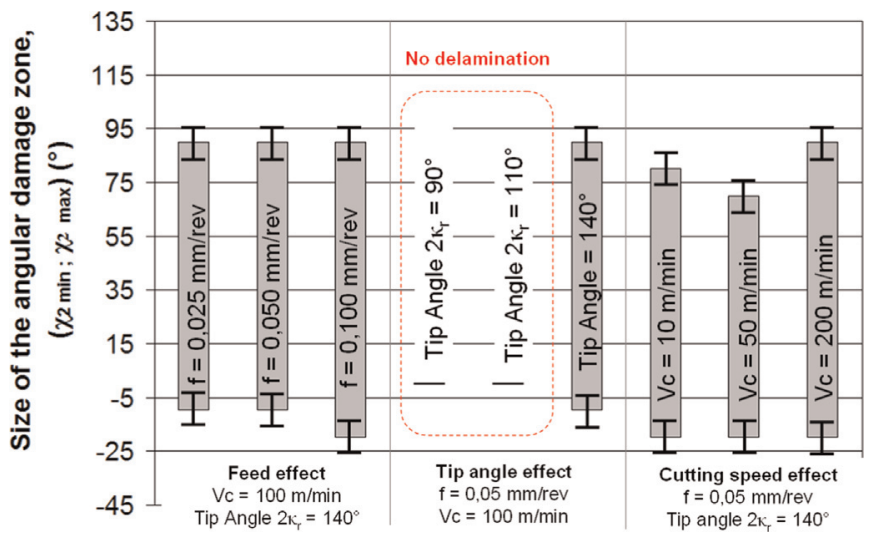

Fig. 6. Variation in the angular damage zone versus feed tip angle and cutting speed.

feed force. The presented model is thus capable of calculating the local linear feed force variation along the cutting edge $(l)$ at various steps of the hole drilling operation.

\subsection{Definition of the input data}

The first input datum in the model is the cutting mode $\chi_{2}$ at different positions along the cutting edge (l). The second datum is the feed force signal $\mathrm{Fz}(l)$ measured during the drilling of a unidirectional CFRP, as illustrated in Fig. 10.

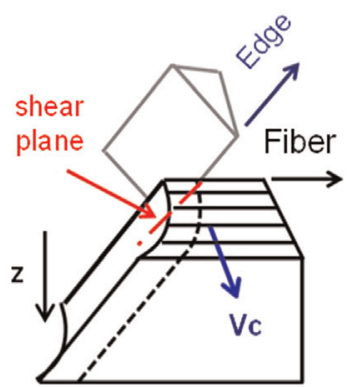

$x_{2}=90^{\circ}$

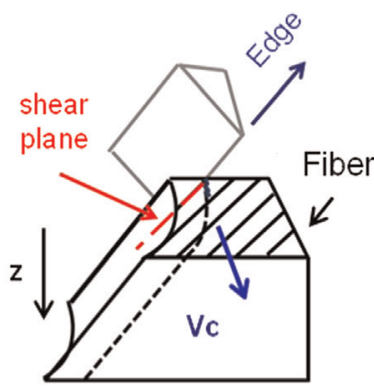

$x_{2}=45^{\circ}$

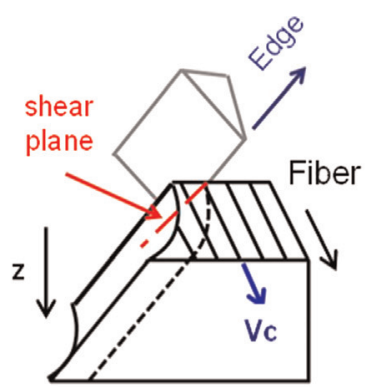

$X_{2}=0^{\circ}$

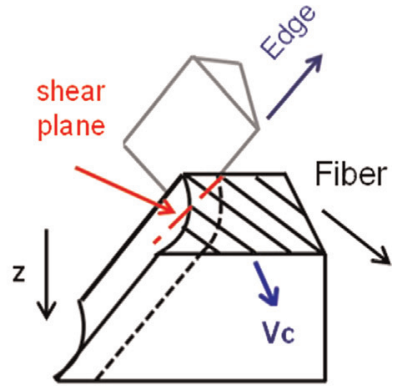

$X_{2}=-45^{\circ}$

Fig. 4. Definition of $\chi_{2}$ cutting modes in CFRP drilling. 


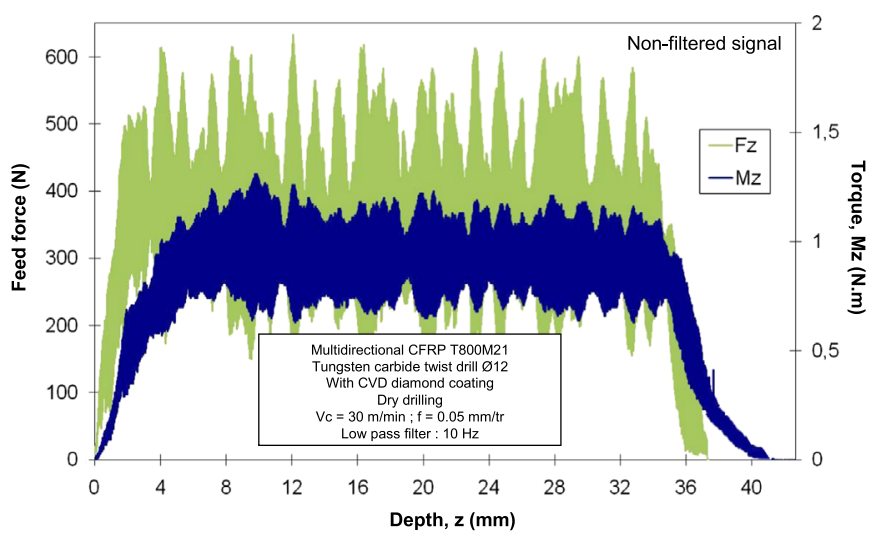

Fig. 7. Feed force and torque variation without filtering.

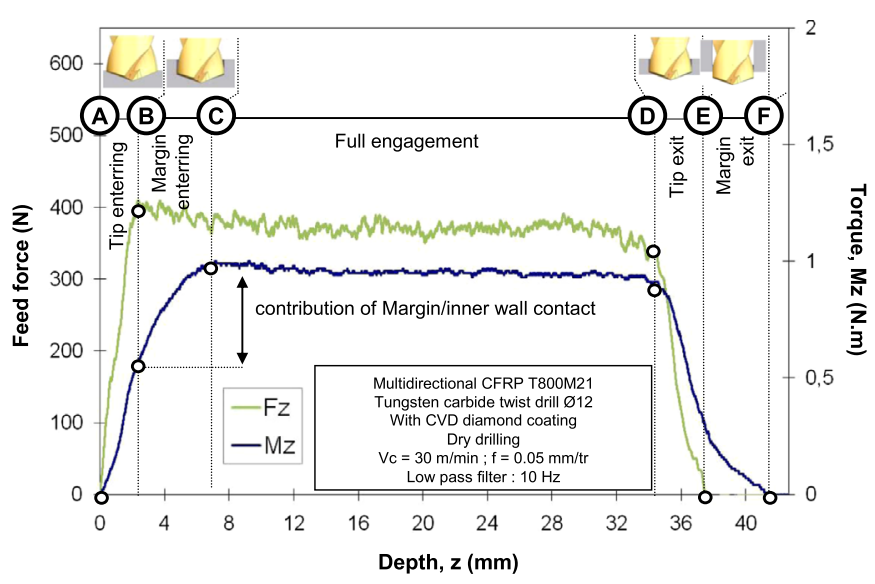

Fig. 8. Feed force and torque variation with a $10 \mathrm{~Hz}$ low pass filter.

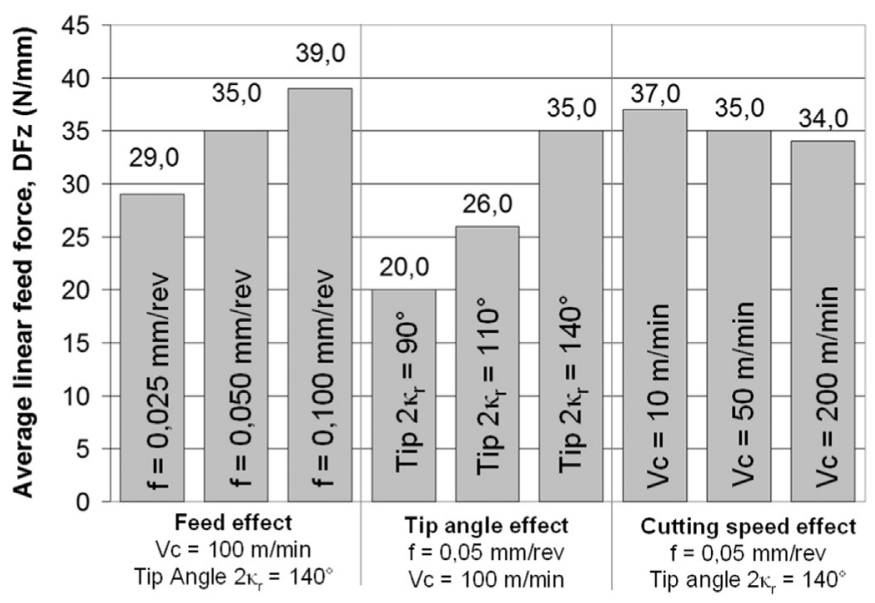

Fig. 9. Variation in average linear feed force versus feed tip angle and cutting speed.

According to the Nyquist-Shannon theorem, the recording frequency of the signal must be higher than $13 \mathrm{~Hz}$, which is the revolution frequency multiplied by the number of lips. The signal displayed in Fig. 10 is thus recorded at $7800 \mathrm{~Hz}$, leading to 600 recordings during a half-revolution of the tool. Consequently, the cutting forces are analyzed with a relevant angular resolution, i.e. $0.3^{\circ}$.

\subsection{Mathematical expression}

The local linear feed force $B\left(\chi_{2}, l\right)$ is a combination of the steady signal and the transient feed force signal. Eq. (1) (local linear feed force) is defined for different fiber cutting modes $\left(\chi_{2}\right)$ at each curvilinear position along the cutting edge $(l)$.

$B\left(\chi_{2}, l\right)=\frac{1}{s} \times\left(F z_{S}{ }^{\prime}(l)+A\left(\chi_{2}\right) \times F z_{T} \max ^{\prime}(l)\right)$

$F z_{\mathrm{S}}(l)$ : is the steady signal of $F z_{\mathrm{s}}(l)$ obtained using a $10 \mathrm{~Hz}$ low pass filter, as mentioned in Fig. 11. It is modeled by a 4 th degree polynomial function. $F z_{\mathrm{S}}(l)=\mathrm{d} F z_{\mathrm{S}}(l) / \mathrm{d} l$ is a linearization to obtain the steady force on a cutting element dl, as illustrated in Fig. 12. Additionally, independence between each segment is assumed in the present study, in accordance with the Edge Material Pair method described by Claudin [13]. Only feed force variation due to the cutting edge geometry is taken into account.

$F z_{T \text { max }}(l)$ : is the envelope of the whole set of maximum values attained by the transient signal $F z_{\mathrm{T}}(l)$ filtered with a $10 \mathrm{~Hz}$ highpass filter, as indicated in Fig. 11 and modeled by a 3rd degree polynomial function.

A $\left(\chi_{2}\right)$ : represents the elementary oscillation of the transient signal $F z_{\mathrm{T}}(l)$ filtered with a $10 \mathrm{~Hz}$ high-pass filter, illustrated in Fig. 13. A sinusoidal curve was chosen to reproduce the transient signal.

$s$ : is the number of cutting edges.

\subsection{Description of the output data}

The first output datum is the local linear feed force distribution along the cutting edge, as described in Fig. 14. It is relevant to note that the local linear feed force is maximum near the drill web and minimum in the corner region. This trend has widely been discussed in the literature by Claudin [13]. It is due to the cutting geometry, which varies along the edge. A larger contribution of the local linear feed force is localized close to the drill web because of the low rake angle value. In addition, the cutting speed is close to zero and in consequence generates indentation phenomena instead of cutting mechanisms. On the contrary, the rake angle is largely positive near the corner $\left(30^{\circ}\right.$ in this case), which facilitates fiber cutting. Discontinuities are observed between successive ply borders when the fiber orientation $\theta$ changes. In the particular case of multidirectional CFRP drilling, different cutting modes $\left(\chi_{2}\right)$ could occur at the same time along the cutting edge $(l)$.

The second output datum is the cartography of the local linear feed force $(\mathrm{d} F z)$ over the exit ply, illustrated in Fig. 15. The maximum local linear feed force is concentrated in hole center region and extends to the inner wall in a large band oriented towards $\chi_{2}=+45^{\circ}$, whereas the minimum is localized only at the circumference and oriented towards $\chi_{2}=-45^{\circ}$. Extreme amplitudes are observed between the different cutting modes. From $\chi_{2}=-45^{\circ}$ to $\chi_{2}=+45^{\circ}$, the local linear feed force increases by $350 \%$. Cutting modes $\chi_{2}=0^{\circ}$ and $\chi_{2}=90^{\circ}$ generate an intermediate feed force level, estimated at around $+200 \%$ compared to $\chi_{2}=-45^{\circ}$. This result outlines the particularity of CFRP cutting and will be discussed in the following section.

\section{Discussion}

Fiber-resin de-cohesion may be generated by too high a local feed force generated by the cutting edge in the exit ply. The cartography of the local linear feed force, modeled in Fig. 16, can be directly correlated with the experimental exit damage observed in Figs. 2 and 3.

The lowest local linear feed force is observed for $\chi_{2}=-45^{\circ}$. This seems to be the most appropriate fiber cutting mode because it corresponds to a minimum force requirement. The primary shear plane, from the edge to the surface, is here orthogonal to the fiber, as indicated in Fig. 16. This appears to be coherent with the very 

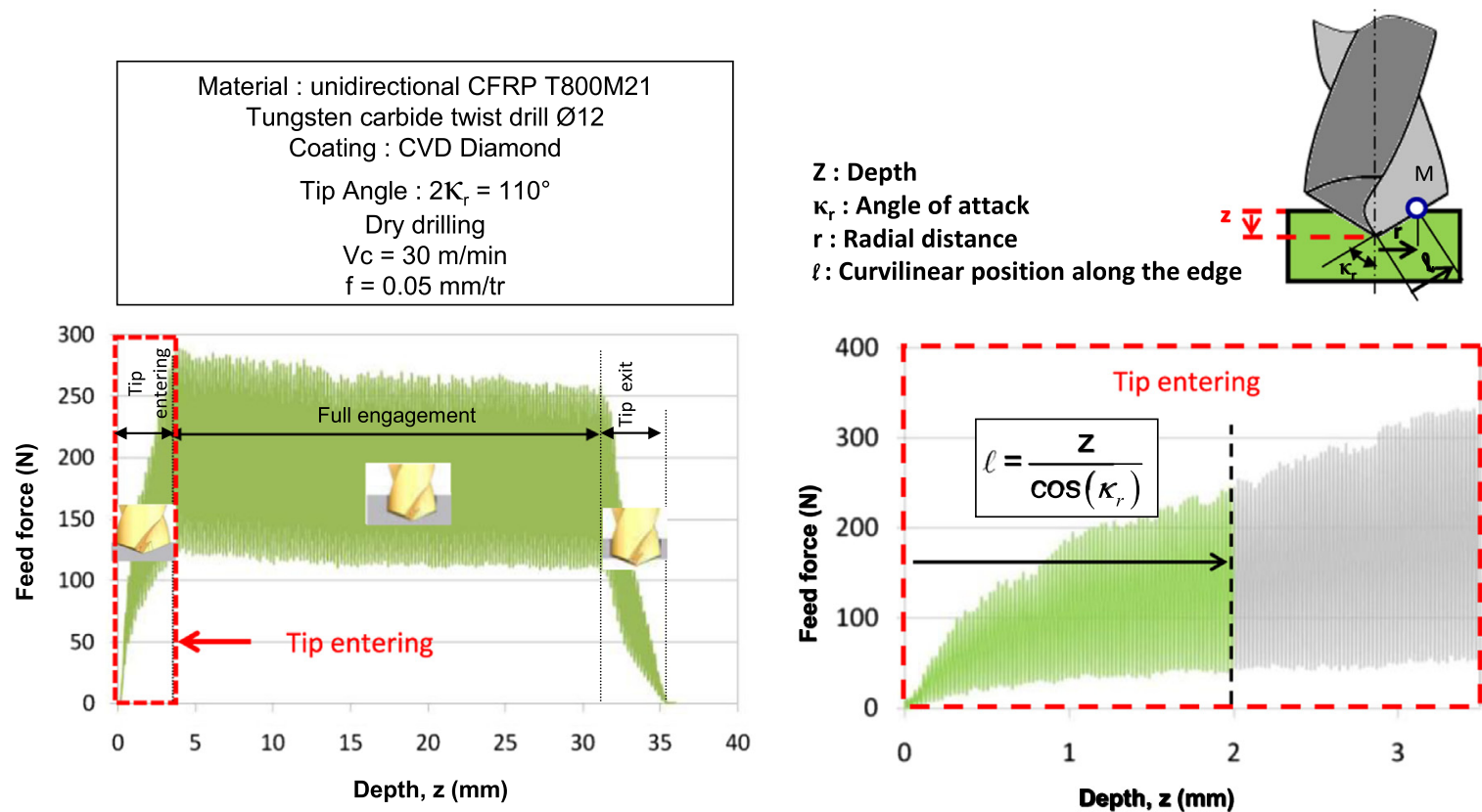

Fig. 10. Feed force measured during unidirectional CFRP drilling.

low shear strength of carbon fibers in the transverse direction. In this case, the delamination risk is low. As confirmed by the experimental observation previously presented in Fig. 6, the damage zone never reaches $\chi_{2}=-45^{\circ}$.

The highest local linear feed force is observed for $\chi_{2}=+45^{\circ}$. This seems to be the worst fiber cutting mode because the fiber directions are collinear to the primary shear plane. In this case the fibers are difficult to shear. The delamination of the last ply appears because there is no more work material to support the mechanical load applied by the cutting edge. The angular size of the damage zone extends from $\chi_{2} \min =-10^{\circ}$ to $\chi_{2} \max =90^{\circ}$ and is concentrated around $\chi_{2}=+45^{\circ}$, as previously illustrated in Fig. 3 .

The limit of the local linear feed force which can avoid fiberresin de-cohesion is discussed here. The experimental results presented in Figs. 4 and 8 underlined that no delamination is observed when the average linear feed force (DFz) does not exceed

Steady signal, with a $10 \mathrm{~Hz}$ low-pass filter

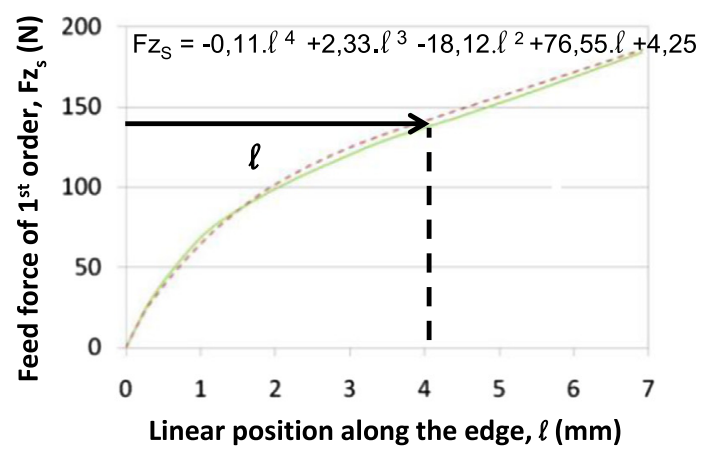

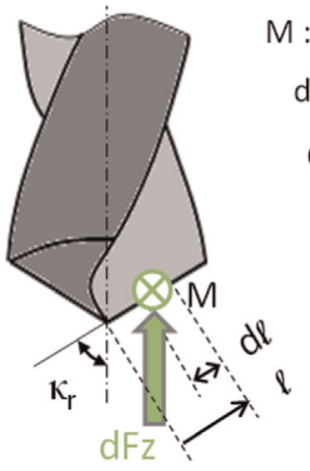

Tip entering

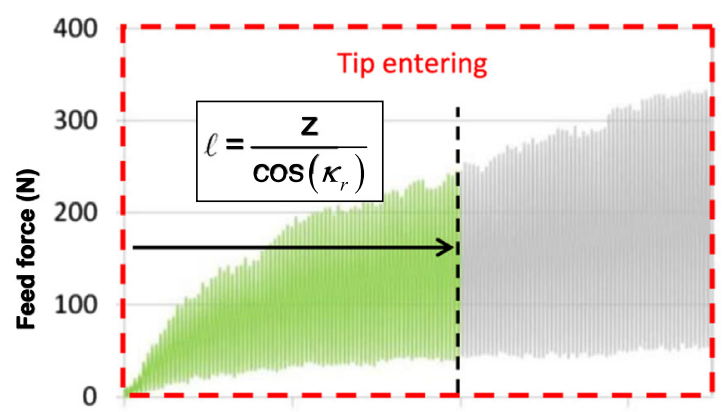$$
0
$$$$
\begin{array}{llll}
0 & 1 & 2 & 3
\end{array}
$$

Depth, 2 (mm)
Fig. 12. Cutting edge discretization method.

Transient signal, with a $10 \mathrm{~Hz}$ high-pass filter

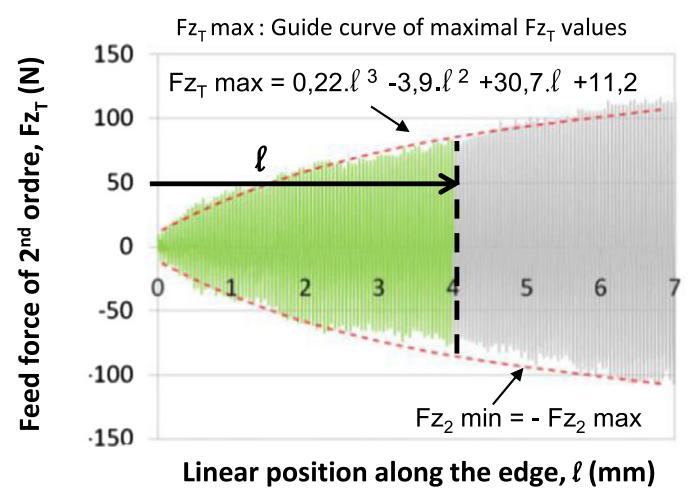

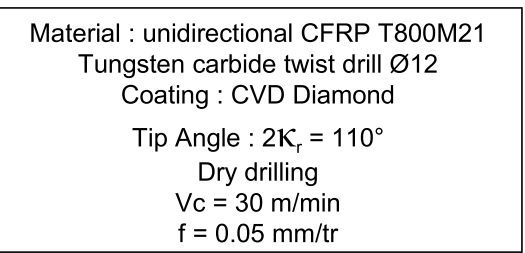

Fig. 11. Decomposition of the feed force signal. 


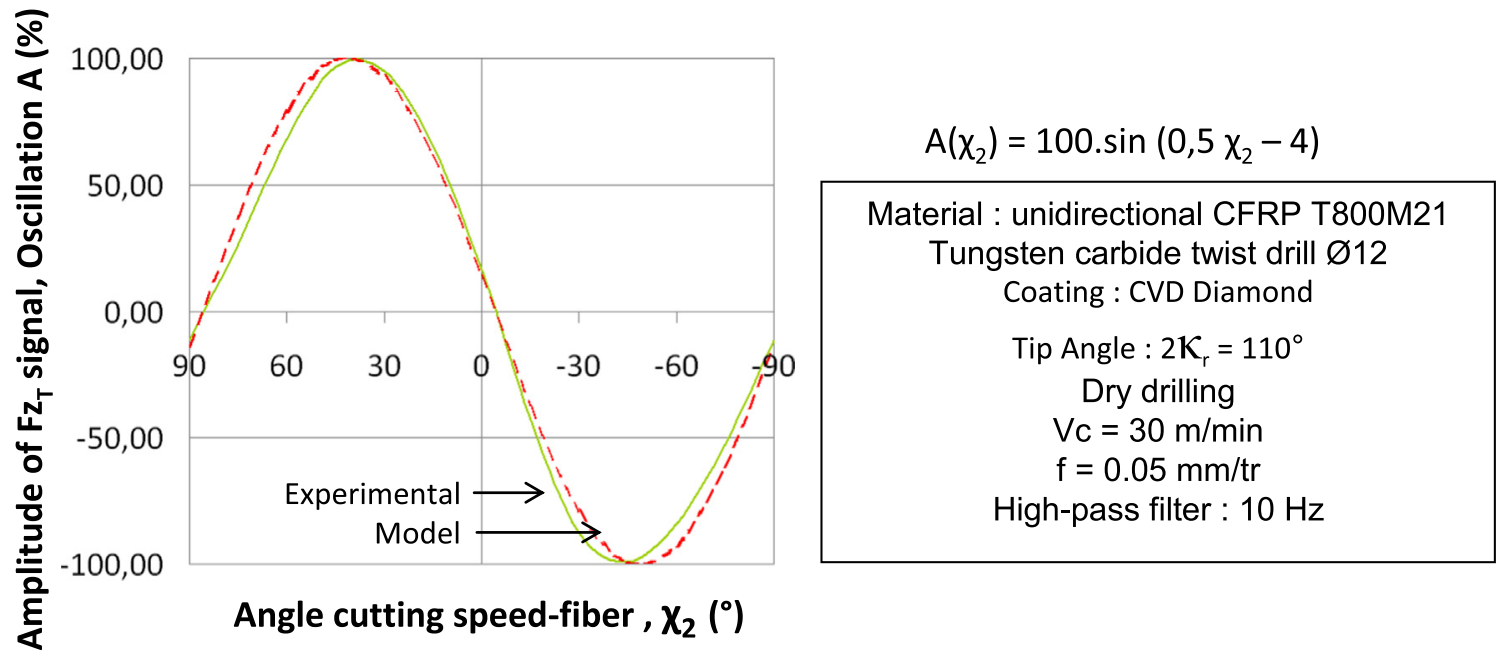

Fig. 13. Elementary oscillation of the transient signal.

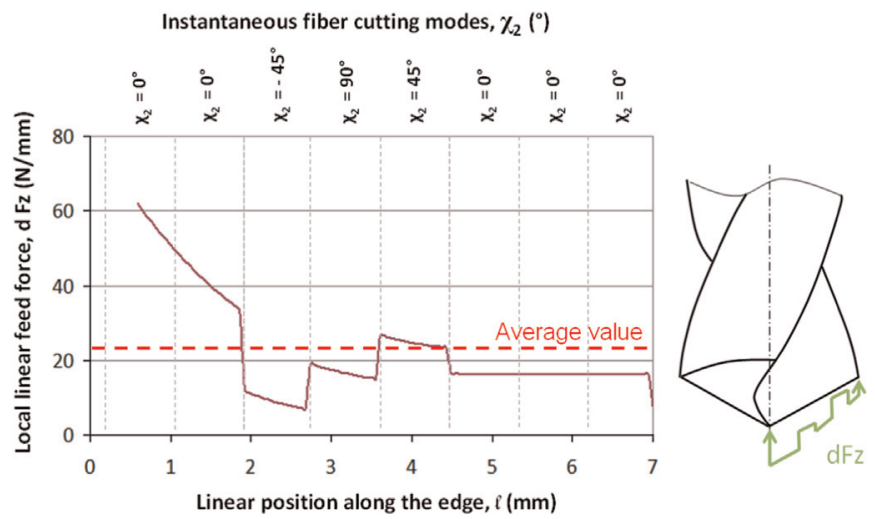

Fig. 14. Local linear feed force along the cutting edge for different cutting modes $\left(\chi_{2}\right)$ in a multidirectional CFRP.
$26 \mathrm{~N} / \mathrm{mm}$. As can be seen in Fig. 15, the local feed force $(\mathrm{d} F \mathrm{z})$ near the inner wall represented about $75 \%$ of the average feed force along the cutting edge. As a consequence, the risk of delamination can be reduced if the local linear feed force on the hole circumference is lower than $\mathrm{d} F z=20 \mathrm{~N} / \mathrm{mm}$. This limit value is partially confirmed by the correlation between Figs. 5 and 14. The cartography of the local linear feed force near the inner wall is illustrated for the cutting condition $f=0.05 \mathrm{~mm} / \mathrm{rev}, V_{\mathrm{c}}=30 \mathrm{~m} / \mathrm{min}$ and with a tip angle of $2 \kappa_{\mathrm{r}}=110^{\circ}$. As a result, the model proposes a value of around $14 \mathrm{~N} / \mathrm{mm}$ to be in agreement with the angular damage zone for angles $\chi_{2} \min =-10^{\circ}$ to $\chi_{2} \max =90^{\circ}$.

\section{Conclusion}

As outlined in the introduction, the literature in composite machining is poor regarding cutting force modeling. Although it

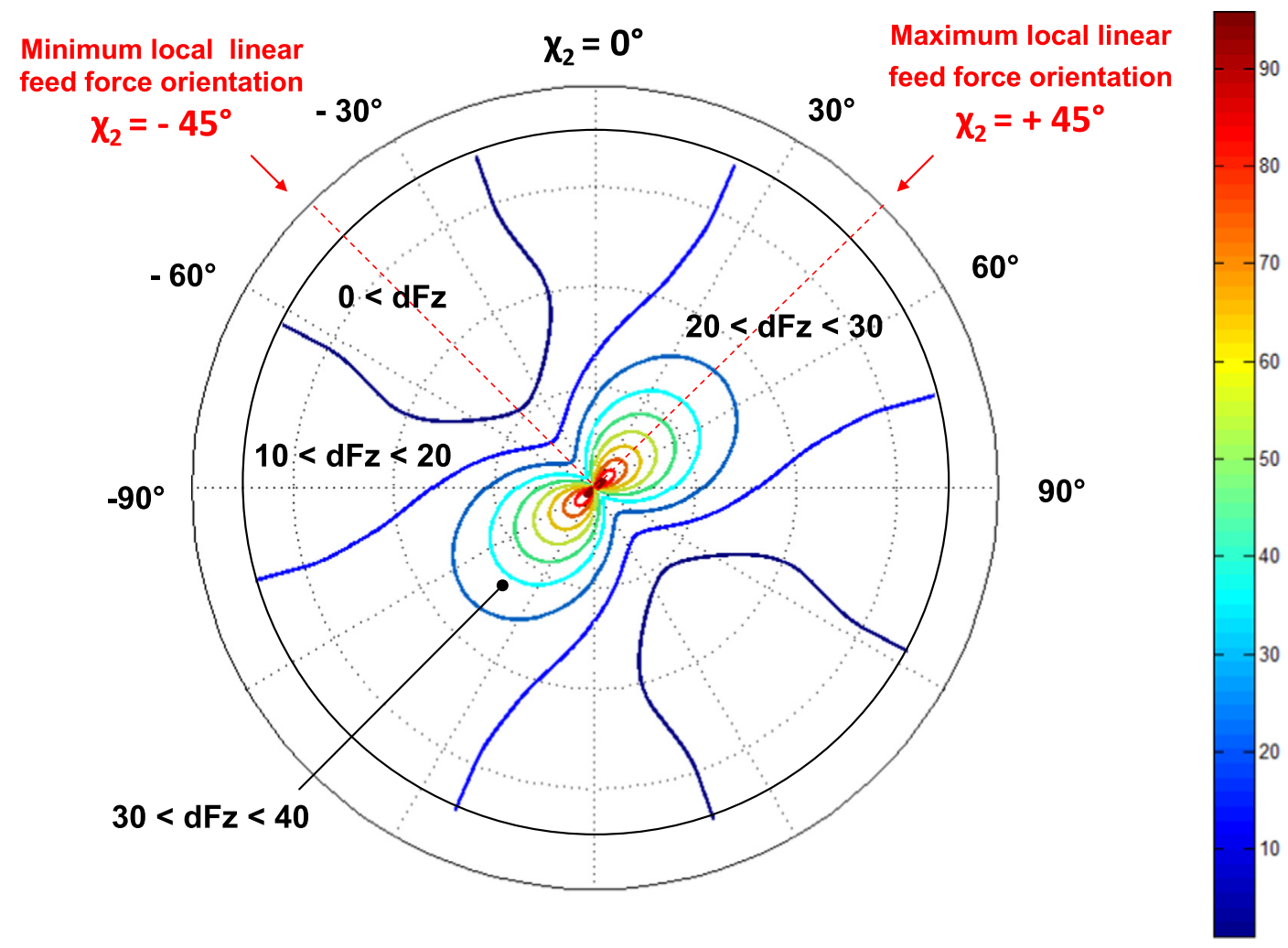

Fig. 15. Cartography of the local linear local feed force $(\mathrm{d} F z)$ in the exit ply. 


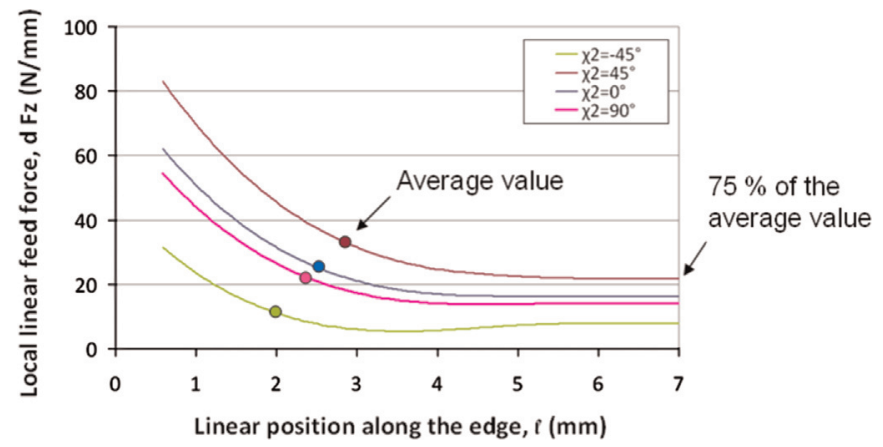

Fig. 16. Local linear feed force for different cutting modes $\chi_{2}$ in CFRP drilling.

has been detected that fiber orientation has a strong influence on the quality of the hole surface, its modeling is still in its early stages. Specific cutting tools similar to those used in wood machining have been developed; their use in the context of this study cannot be applied because of the presence of metallic material in the machined stack.

Consequently it is necessary to have a better understanding of the cutting process, particularly when the tool reaches the hole exit.

In the majority of past studies, the effect of instantaneous fiber orientation on the cutting edge is not taken into account in the model of the local feed force and its consequences on delamination.

Precisely, this study proposes a specific model in order to understand the role of the local feed force in CFRP drilling delamination. The mechanical load generated by the cutting edge over the exit ply is measured and analyzed with respect to fiber orientation. In the model developed here, the cutting forces are resolved into transient and steady components. Since the loading depends on the cutting edge geometry and on the fiber cutting mode, it continuously changes during a drill revolution. As a result, a cartography of the local feed force $(\mathrm{d} F z)$ with respect to fiber orientation is proposed. The main results are summarized here:

- The issues of this experimental study are first of all a better understanding of hole exit damage in T800M21.

- The correlation between fiber orientation and surface quality in the inner wall of the hole is established.

- The maximum local feed force is concentrated at the hole center and extends in a large angular band oriented from angles $\chi_{2} \min =-10^{\circ}$ to $\chi_{2} \max =90^{\circ}$. The peak force is reached for $\chi_{2}=+45^{\circ}$.
- The cutting mode $\chi_{2}=+45^{\circ}$ appears to be the worst cutting configuration. The risk of delamination is maximum in this area if the local feed force exceeds the fiber-resin de-cohesion limits, estimated at between $14 \mathrm{~N} / \mathrm{mm}$ and $20 \mathrm{~N} / \mathrm{mm}$ near the inner wall.

In the future, these results could be useful at the design stage, particularly regarding how the last ply is sized. Moreover, in a production context, force modeling may help to avoid delamination by managing the feed rate close to the tool exit.

This work was carried out with the help of a grant from the AIRBUS GROUP and SECOTOOLS companies.

\section{References}

[1] E. Persson, I. Eriksson, L. Zackrisson, Effects of hole machining defects on strength and fatigue life of composite laminates, Compos. Part A: Appl. Sci. Manuf. 28 (2) (1997) 141-151.

[2] D.H. Wang, M. Ramulu, D. Arola, Orthogonal cutting mechanisms of graphite epoxy composite. Part I: unidirectional laminate, Int. J. Mach. Tools Manuf. 35 (12) (1995) 1623-1638.

[3] D. Arola, M. Ramulu, D.H. Wang, Chip formation in orthogonal trimming of graphite/epoxy composite, Compos. Part A: Appl. Sci. Manuf. 27 (2) (1996) 121-133.

[4] V. Krishnaraj, A. Prabukarthi, A. Ramanathan, N. Elanghovan, M. Senthil Kumar, R. Zitoune, J.P. Davim, Optimization of machining parameters at high speed drilling of carbon fiber reinforced plastic (CFRP) laminates, Compos. Part B: Eng. 43 (4) (2012) 1791-1799.

[5] R. Piquet, B. Ferret, F. Lachaud, P. Swider, Experimental analysis of drilling damage in thin carbon/epoxy plate using special drills, Compos. Part A: Appl. Sci. Manuf. 31 (10) (2000) 1107-1115.

[6] J.P. Davim, P. Reis, C. Conceição António, Experimental study of drilling glass fiber reinforced plastics (GFRP) manufactured by hand lay-up, Compos. Sci. Technol. 64 (2) (2004) 289-297.

[7] R. Zitoune, F. Collombet, Numerical prediction of the thrust force responsible of delamination during the drilling of the long-fibre composite structures, Compos. Part A: Appl. Sci. Manuf. 38 (3) (2007) 858-866.

[8] C.C. Tsao, Investigation into the effects of drilling parameters on delamination by various step-core drills, J. Mater. Process. Technol. 206 (1-3) (2008) 405-411.

[9] M. Ramulu, T. Branson, D. Kim, A study on the drilling of composite and titanium stacks, Compos. Struct. 54 (2001) 67-77.

[10] A. Mondelin, B. Furet, J. Rech, Characterisation of friction properties between a laminated carbon fibres reinforced polymer and a monocrystalline diamond under dry or lubricated conditions, Tribol. Int. 43 (9) (2010) 1665-1673.

[11] W.M. McKenzie, Fundamental aspects of the wood cutting process, For. Prod. J. Issue 10 (1960) 447-456.

[12] P. Ghidossi, Contribution à l'étude de l'effet des conditions d'usinage d'éprouvettes en composites à matrice polymère sur leur réponse mécanique, 2003, Ph.D. thesis.

[13] C. Claudin, G. Poulachon, M. Lambertin, Correlation between drill geometry and mechanical forces in MOL conditions, Mach. Sci. Technol. 12 (1) (2008) 133-144. 